\title{
Household air pollution and COVID-19 risk in India: A potential concern
}

\author{
Rachit Sharma ${ }^{1}$ and Md Mahbub Hossain ${ }^{2}$
}

\begin{abstract}
One in every two Indian households continues to rely on highly-polluting solid fuels to meet their cooking and other energy demands. Recent evidence demonstrates that people suffering from preconditions associated with air pollution and those with shortterm exposures to air pollution are highly susceptible to the novel Coronavirus infection and associated morbidity and mortality. And as for many Indians, especially those with pre-existing health conditions and the elderly, home-based isolation and confinement practices are likely to continue to prevent the infection, exposure to household air pollution may render such population groups more susceptible to COVID-19. This warrants caution and demands immediate and specific actions; which are discussed. To protect the health and wellbeing of millions of Indians, during the COVID-19 crisis and beyond, addressing household air pollution should be prioritized and aligned with long term environmental health initiatives in the country.
\end{abstract}

\section{Keywords}

COVID-19; Coronavirus; SARS-CoV-2; household air pollution; solid fuels; biomass; indoor air; India

\footnotetext{
${ }^{1}$ GRID Council, Delhi-NCR 201301, India.

${ }^{2}$ Department of Health Promotion and Community Health Sciences, Texas A\&M School of Public Health, TX 77843, USA.
}

Corresponding Author: Rachit Sharma, GRID Council, Delhi-NCR 201301, India. 


\section{Introduction}

India has been under a nationwide lockdown since March 25, 2020, in response to the COVID-19 pandemic. While many Indian states and districts plan and execute their lockdown exit strategies, home-based isolation and confinement practices are much likelier to continue for those with pre-existing health conditions and the elderly - the most visible victims of COVID-19. This necessitates the need to acknowledge and critically evaluate household environmental factors that may render such vulnerable population groups more susceptible to COVID-19 as they continue to self-isolate at homes.

The presence of co-morbidities is one of the major risk factors aggravating the impact of COVID-19. And air pollution, particularly household air pollution (HAP), contributes substantially to India's disease burden, accounting for a myriad of adverse health outcomes including respiratory, cardio-metabolic, neuro-behavioral and developmental disorders, and premature deaths. ${ }^{(1)}$ In 2017, HAP alone accounted for nearly 16 million disability-adjusted life years and claimed more than half a million lives across the country. ${ }^{(1)}$ Though in India ambient air pollution levels have drastically plummeted due to the lockdown, exposure to HAP can be expected to be exponentiated as most citizens are confined to their homes and will continue to do so during the COVID-19 era. ${ }^{(2)}$ This is of special concern as about one in every two Indian households continues to rely on highly-polluting solid fuels (wood, dung, agricultural residues, coal, and charcoal) for cooking, heating, and other energy services. ${ }^{(1)}$

\section{Air Pollution and COVID-19 Risk}

One of the most common and major health deterrent combustion products of solid-fuels is fine particulate matter $\left(\mathrm{PM}_{2.5}\right.$, particulate matter with an aerodynamic diameter less than $2.5-\mu \mathrm{m}) .{ }^{(1)}$ Recent evidence demonstrates that people suffering from preconditions associated with $\mathrm{PM}_{2.5}$ exposure are highly prone to the novel Coronavirus (SARS-CoV-2) infection and associated morbidity and mortality. A nationwide cross-sectional analysisin the United States found out that a $1-\mu \mathrm{g} / \mathrm{m}^{3}$ rise in $\mathrm{PM}_{2.5}$ concentration increases the odds of COVID-19 mortality by $8 \%$ (95\% confidence interval [CI]: 2-15\%). ${ }^{(3)}$ 
An analysis of 120 Chinese cities established significantly positive associations between short-term exposure (over prior 2 weeks) to $\mathrm{PM}_{2.5}$ and with newly confirmed COVID-19 cases; with a $10-\mu \mathrm{g} / \mathrm{m}^{3}$ increase in $\mathrm{PM}_{2.5}$ being associated with a $2.24 \%$ (95\% CI: $1.02-$ $3.46 \%$ ) increase in the daily counts of confirmed cases. ${ }^{(4)}$ In the Netherlands, a similar analysis of 355 municipalities estimated that a 20 percent rise in $\mathrm{PM}_{2.5}$ concentration led to an increment in the number of newly confirmed COVID-19 cases by nearly 100 percent. ${ }^{(5)}$

Experimental studies suggest that particulate matter induced oxidative stress, immunosuppression, reduced ability of macrophages to phagocytize viruses, alteration of the function of surfactant proteins SP-A and SP-D, and increased permeability of the pulmonary epithelium are some of the potential mechanisms underlying the association between particulate matter pollution and respiratory viral infections. ${ }^{(6)}$

Furthermore, researchers are now exploring the potential role various air pollutants can themselves have in the transmission of SARS-CoV-2; with preliminary findings suggesting that SARS-CoV-2, under stable atmospheric conditions and high concentrations of particulate matter could form clusters with particulate matter and reduce its diffusion coefficient, enhancing the persistence of the virus in the atmosphere and augmenting its infectivity. ${ }^{(7)}$

\section{The Way Forward}

For its likelihood to increase the risk of COVID-19 through HAP-mediated health effects and from the household air pollutants as such, the existing public health challenge of HAP in India warrants caution and demands immediate and specific actions.

First, from a research perspective, epidemiological investigations must explore the associations between HAP exposure and COVID-19 risk in the country. For this, personal exposure measurements, individual time-location-activity patterns, socio-economic and ethno-cultural differences, and exposure and health implications of various public health measures undertaken to reduce the transmission of 
SARS-CoV-2 should be considered and accounted for. Second, the health authorities must communicate about the need for maintaining maximum ventilation at homes to minimize health risks from poor household air quality. With the latest evidence suggesting that the genetic material (RNA) of SARS-CoV-2 can persist for hours in the air in crowded or poorly ventilated spaces, aiding its transmission, the benefits of ensuring optimal ventilation could be even more far-reaching in protecting population health. ${ }^{(8)}$ Third, public health agencies and institutional partners should ensure robust door-step delivery mechanisms for clean cooking fuels (Liquified Petroleum Gas/LPG) under the ongoing livelihood support interventions, especially for households not included under the umbrella of Pradhan Mantri Ujjwala Yojana (PMUY). The PMUY aims to provide a subsidy and loan to eligible 100 million below-poverty-line Indian households to cover the upfront cost of acquiring an LPG connection. And under the Indian government's COVID-19 economic relief package for the poor, the scheme of three LPG refills at no cost for a period of three months (April to June 2020) has been extended to the existing PMUY customer base of about 83 million households. ${ }^{(9)}$ However, this leaves out the remainder of the 17 million eligible households, which should be targeted. Last, post-COVID-19, the government must bolster its endeavors for deeper diffusion and sustained use of clean cooking fuels and systems under PMUY. While a considerable number of households have benefited from PMUY since it got implemented in 2016, issues such as recurring gas refill expenses, free access to solid cooking fuels, household financial instability, and poor LPG availability and accessibility in rural areas continue to hinder the adoption of LPG as the primary household fuel. ${ }^{(10)}$ Such issues must be acknowledged and addressed in the long-run.

\section{Conclusion}

Household air pollution, though a long-standing population health challenge in India, presents itself as a renewed health crisis in the country for its probability of increasing the risk of development of COVID-19 and associated health disparities among vulnerable population groups. Therefore, to protect the health and wellbeing of millions of Indians, during the COVID-19 crisis and beyond, addressing household air pollution should be prioritized and aligned with long term environmental health initiatives in the country. 
Acknowledgment: None.

Conflict of interest: We declare no conflict of interest.

Funding: No funding was received at any stage of preparing this manuscript.

\section{References:}

1. Balakrishnan K, Dey S, Gupta T, Dhaliwal RS, Brauer M, Cohen AJ, et al. The impact of air pollution on deaths, disease burden, and life expectancy across the states of India: the Global Burden of Disease Study 2017. Lancet Planet Heal. 2019;3:e2639. Available from: https://doi.org/10.1016/S2542-5196(18)30261-4

2. Sharma S, Zhang M, Anshika, Gao J, Zhang H, Kota SH. Effect of restricted emissions during COVID-19 on air quality in India. Sci Total Environ. 2020;728:138878. Available from: https://doi.org/10.1016/j.scitotenv.2020.138878

3. Wu X, Nethery RC, Sabath MB, Braun D, Dominici F. Exposure to air pollution and COVID-19 mortality in the United States: A nationwide cross-sectional study. medRxiv. 2020; Available from: https://doi.org/10.1101/2020.04.05.20054502

4. Zhu Y, Xie J, Huang F, Cao L. Association between short-term exposure to air pollution and COVID-19 infection: Evidence from China. Sci Total Environ. 2020;727:138704. Available from: https://doi.org/10.1016/j.scitotenv.2020.138704

5. Andree B. Incidence of COVID-19 and Connections with Air Pollution Exposure: Evidence from the Netherlands. medRxiv. 2020; Available from: https://doi.org/10.1101/2020.04.27.20081562

6. Ciencewicki J, Jaspers I. Air pollution and respiratory viral infection. Inhal Toxicol. 2007;19(14):1135-46.

7. Liu Y, Ning Z, Chen Y, Guo M, Liu Y, Gali NK, et al. Aerodynamic analysis of SARSCoV-2 in two Wuhan hospitals. Nature. 2020; Available from: https://doi.org/10.1038/s41586-020-2271-3

8. Setti L, Passarini F, De Gennaro G, Baribieri P, Perrone MG, Borelli M, et al. SARSCov-2 RNA Found on Particulate Matter of Bergamo in Northern Italy: First Preliminary Evidence. medRxiv. 2020; Available from: https://doi.org/10.1101/2020.04.15.20065995

9. The Economic Times. Ujjwala beneficiaries to get 3 free cylinders till June. 2020 Mar 26; Available from: https://economictimes.indiatimes.com/industry/energy/oil-gas/ujjwalabeneficiaries-to-get-3-free-cylinders-till-june/articleshow/74831478.cms

10. Mani S, Jain A, Tripathi S, Gould CF. The drivers of sustained use of liquified petroleum gas in India. Nat Energy. 2020; Available from: https://doi.org/10.1038/s41560-020-0596-7 